\title{
Medicalização do corpo da mulher e criminalização do aborto no Brasil
}

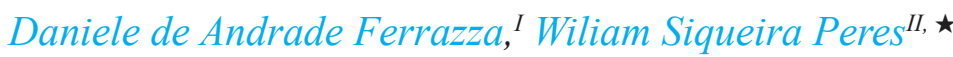 \\ ${ }^{I}$ Universidade Estadual de Maringá, UEM, Maringá, PR, Brasil \\ II Universidade Estadual Paulista "Júlio de Mesquita Filho", Assis, SP, Brasil
}

\begin{abstract}
Resumo
O presente trabalho tem como objetivo refletir sobre a medicalização do corpo e a criminalização do aborto no âmbito do gerenciamento de população de caráter biopolítico. A criminalização do aborto no Brasil permitirá que mulheres pobres se submetam as precárias formas de descontinuação da gravidez e sejam brutalmente vítimas dessa opção. A "vida matável” dessas mulheres não está somente desprovida de direitos, mas da própria qualidade do humano. A descriminalização deve romper com discursos médicos morais para promover o atendimento público para mulheres que queiram optar pela prática do aborto, sem discriminação de raça, credo, etnia e classe social.
\end{abstract}

Palavras-chave: medicalização; controle biopolítico; aborto.

\section{Medicalization of woman's body and criminalization of abortion in Brazil}

\begin{abstract}
This paper aims to reflect about the medicalization of the body and the criminalization of abortion in the range of population management of biopolitical character. The criminalization of abortion in Brazil will allow poor women to undergo the precarious forms of discontinuation of pregnancy and are brutally victims of this option. The "killable life" of these women is not only devoid of rights but of the quality itself of the human. Decriminalization must break with moral medical addresses to promote the public service for women who wish to opt for abortion, without discrimination of race, belief, ethnics and social status.
\end{abstract}

Keywords: medicalization; biopolitical control; abortion.

\section{Introdução}

Um dos grandes exemplos de mulheres e de inteligência feminina, Hipátia de Alexandria, filha de Theon, um importante filósofo e matemático grego, se destacou na antiguidade clássica por seus estudos em astronomia, filosofia e matemática. A posição de mulher e sua defesa ao livre pensamento culminariam em sua morte brutal quando um grupo de cristãos enfurecidos a atacaria e a arrastaria para o interior de um templo onde seria cruelmente apedrejada e torturada até sua morte. Vítima de intolerância e preconceitos políticos e religiosos, Hipátia de Alexandria poderia ser representante de muitas das mulheres que, ainda nos dias de hoje, sofrem com atos de violência, preconceito e opressão.

As mulheres brasileiras, após décadas de lutas por direitos iguais, obtiveram importantes conquistas. Entretanto, muito das violências, opressões e preconceitos ainda permanecem. Nesse panorama, o presente trabalho tem como objetivo apresentar problematizações sobre a criminalização do aborto no Brasil no âmbito do gerenciamento de população de caráter biopolítico e do processo de medicalização da existência humana que lhe é inerente.

A questão do aborto, como demonstrou a exploração do tema pela demagogia política em eleições presidenciais no Brasil, ainda é uma problemática marcada por mitos e preconceitos morais que impedem a problematização mais fundamentada e discussões mais sérias sobre a descriminalização desse direito feminino em nosso país.

\footnotetext{
^Endereço para correspondência: Universidade Estadual de Maringá - UEM, Departamento de Psicologia. Av. Colombo, 5.790 - Campus Universitário. CEP 87.020-900 - Maringá, PR - Brasil. E-mail: danieleferrazza@yahoo.com.br, pereswiliam@gmail.com
}

O plano de apresentação dessas questões consiste, primeiramente, na exploração da noção de medicalização do social e de patologização da existência em suas interfaces com classes, raças/cores, sexos, gêneros e gerações, processos que nos remetem a fenômenos complexos, polêmicos, multifacetados e que estão entrelaçados às estratégias políticas de gerenciamento da vida humana e suas intenções de normatização regulatória dos corpos e de seus prazeres. Em um segundo momento, este trabalho aborda a permanência desse processo de gerenciamento dos corpos das mulheres a partir da noção de controle biopolítico, concepção orientada conforme Michel Foucault como desenvolvimento de uma sociedade caracterizada como disciplinar. Em um terceiro momento, este estudo examina a questão das sexualidades e de sua relação com o processo de medicalização da vida e das estratégias de controle biopolítico sobre os corpos das mulheres. Em um quarto momento, o artigo explora algumas problemáticas referentes à criminalização do aborto no Brasil e suas amarras médicas, psicológicas, jurídicas, morais. E, finalmente, analisa a questão da medicalização dos corpos das mulheres e examina as concepções sobre o "caráter matável" (AGAMBEN, 2002) daquelas mulheres pobres que optam pela prática do aborto e que estão inseridas em contextos desfavoráveis que se intensificam mais ainda se elas forem negras, solteiras e dissidentes do sistema sexo/ gênero/desejo/práticas sexuais (BUTLER, 2003).

Medicalização do social e gerenciamento da vida humana

O processo de medicalização do social é um movimento complexo que envolve inúmeras questões epistemológicas, filosóficas, sociais, políticas e culturais. A noção de medicalização pode ser compreendida como uma forma da medicina se apropriar dos fenômenos relacionados à 
existência humana e transformá-los em objetos da ordem médica, submetidos a processos de normatização dos corpos, de suas práticas sociais e sexuais, assim como, de seus prazeres (TOASSA, 2012; FOUCAULT, 2010; TESSER, 2010; COSTA et. al., 2006; ILLICH, 1975). Nessa configuração, a medicalização do social e das sexualidades é um processo pelo qual a medicina, por meio de inúmeras tecnologias e estratégias, irá interferir na construção de conceitos, normas, regras de higiene, costumes e comportamentos alimentares, sexuais e sociais prescritos para governar a vida dos homens e das mulheres em processos de gerenciamento humano e controle biopolítico (GALINDO; LEMOS; RODRIGUES, 2014; FOUCAULT, 2002, 2010; HORA, 2006).

As críticas ao processo de medicalização da sociedade surgiram na segunda metade do século XX, quando intelectuais como Illich (1975) e Foucault (2010), teceriam apontamentos sobre a expansão das práticas e discursos médicos em toda a sociedade por meio da determinação de novos diagnósticos, da criação de novos medicamentos, da introdução de novas técnicas de intervenção terapêutica e a criação de novas áreas de pesquisas como a genética, a imunologia, a biotecnologia. (POLI NETO; CAPONI, 2010). No entanto, esse papel normativo e gerenciador da vida humana, muito debatido nos tempos atuais, já estavam presentes nas origens do movimento higienista europeu a partir do sec. XVIII, quando a medicina higienista interviria nas questões sobre as sexualidades, sobre as classes sociais, sobre as raças/cores, sobre as gerações. E se encarregaria de estigmatizar todos aqueles e aquelas que não se enquadravam às classes burguesas e brancas e não se adaptavam às relações monogâmicas falocêntricas heterossexuais e determinaria rótulos sobre as "loucuras morais", as "degenerescências", as "anormalidades", as "vadiagens", as "libertinagens" (FOUCAULT, 1997), em um processo de patologização da existência humana.

Os processos de gerenciamento político e controle da vida humana sempre estiveram atrelados aos saberes, poderes e práticas médicas que visavam intervenções em toda a sociedade. Essas práticas se articulavam aos regimes de verdades que se efetivavam através de discursos disciplinares e regulatórios advindos de referências moralistas cristãs e da forte aliança com o Estado na sua gerência do capital, o que por sua vez, clarificava que esses processos apresentavam-se ainda mais evidentes nas camadas mais pobres da população (FOUCAULT, 1997). No regaste das origens da constituição histórica desses processos de gerenciamento populacional e moralização das massas, é possível encontrar nas práticas daquela medicina higienista de fins do sec. XVIII e início do sec. XIX indícios de que os problemas e os riscos sempre estiveram relacionados à população pobre, processo marcado, inclusive, pela ocultação das atrocidades da violência estrutural que geraria modos de estigmatização e de desigualdades sociais, sexuais, políticas, culturais e de gênero. Conforme explicitado por Castel (1978, p. 262):
Apesar da sociedade inteira estar no horizonte de uma intervenção preventiva, são evidentemente seus pontos fracos os focos de desordem e de miséria, que serão prioritariamente visados. É sobretudo para uma 'moralização das massas' que a medicina mental deve contribuir, ajudando no encargo dessas 'classes declinantes que mal entreveem o movimento ascendente das classes superiores e que não podem atingi-lo se forem abandonadas às suas próprias forças'.

Essa tendência se tornaria superlativa no higienismo da segunda metade daquele século e pautaria a permanência desses gerenciamentos na contemporaneidade, trajeto este que seria estudado por Michel Foucault sob a noção de sociedade disciplinar e, em seu desenvolvimento, sob a noção de controle de população que denominou de biopolítica (FOUCAULT, 1982, 2002). De modo complementar e de acompanhamento dos processos de subjetivação atualizados, Gilles Deleuze (1999) contribuiria com problematizações sobre os dispositivos de regulação que caracterizariam a sociedade de controle.

\section{Sobre a sociedade disciplinar e as regulações biopolíticas}

A partir do século XVII, se espalhariam por toda a Europa grandes estabelecimentos de internação, nos quais seriam trancados doentes, mendigos, prostitutas, loucos, órfãos, aleijados, rebeldes, incapacitados e todos aqueles considerados inconvenientes. Essas seriam as instituições de grande enclausuramento de pobres que apresentariam como característica uma mistura de punição, assistência e trabalhos forçados (FOUCAULT, 1982).

Na passagem do século XVIII para o século XIX, a partir desses estabelecimentos de grande aprisionamento de pobres e de dissidentes da norma, se faria o recorte criador das modernas instituições disciplinares, cujos exemplos mais marcantes seriam as prisões e os manicômios (FOUCAULT, 1984; 1996). Segundo Deleuze (1999, p. 219) aquela seria a época em que os indivíduos passariam de um espaço fechado para outro, cada um com suas características e leis próprias: "primeiro a família, depois a escola, depois a caserna, depois a fábrica, de vez em quando o hospital e eventualmente a prisão que é, por sua vez, o meio de confinamento por excelência". Naquela sociedade caracterizada pelas instituições disciplinares o objetivo seria gerenciar a vida dos homens e das mulheres com o intuito de aproveitar ao máximo sua força de trabalho e reduzir ao mínimo suas capacidades de lutas e de resistências políticas (MACHADO, 1982).

Conforme Foucault (2006), as disciplinas, que se originariam dessas práticas de reclusão, seriam técnicas de controle e distribuição dos corpos, dos indivíduos, dos tempos, das forças de trabalho, mas também, das práticas sexuais, dos regimes de prazeres (dietética), das expressões de gêneros, em consonâncias com sistemas perceptivos e sensoriais, sistemas de pensamentos e dos processos desejantes. Seriam formas de disciplinar, regular e distribuir essas vidas e possibilitar a constituição de saberes e poderes sobre os indivíduos que surgiriam de suas classificações, dos registros e das análises de seus comportamentos (FOUCAULT, 1996). Essa seria a origem dos saberes clínicos, do tipo da psiquiatria, da sexologia, da 
psicologia, da sociologia, da criminologia. Saberes disciplinares que iriam decompor todos os elementos característicos dos sujeitos - corpos, sexos, gêneros, desejos, práticas sexuais, atitudes, comportamentos - para comparar e avaliar, de um lado, suas potencialidades, virtualidades, qualidades e, de outro, seus problemas, defeitos, vícios, incapacidades. Em torno dessa lógica binária com tendência universalista se constituí dois grandes conjuntos categóricos: o primeiro composto por corpos considerados economicamente produtivos e úteis para as demandas e exigências sociais da época, assim como, dóceis e submissos aos mecanismos do biopoder; o segundo grupo seria constituído por corpos improdutivos e nocivos, caracterizados pelos loucos, criminosos, doentes e dissidentes do sistema sexo/gênero/desejo/práticas sexuais (BUTLER, 2003), limitados aos regimes de verdades heteronormativos e falocêntricos (BRAIDOTTI, 2002). Estamos falando de procedimentos regulatórios que produziram esquadrinhamentos disciplinares e que promoveram adestramentos e controles permanentes, dispositivos eficientes para a transformação e normalização daqueles rotulados como desajustados, dissidentes, inaptos e fora da norma, ou seja, todos aqueles e aquelas que resistem aos imperativos dos discursos normativos.

No entanto, segundo Foucault (1982, 1997), ao mesmo tempo em que as relações de poder em seus aspectos negativos disseminam o controle, a tutela, a proibição, a censura, a interdição, os mecanismos de poder que regulamentam também as práticas sexuais se mantém e são aceitos por produzirem saberes, discursos e prazeres. As estratégias de poder envolvem forças que se chocam e também se contrapõem, em processos de disciplinamentos de corpos, mas também de criação e produção de subjetividades. Desta forma,

Temos que deixar de descrever sempre os efeitos do poder em termos negativos: ele 'exclui', 'reprime', 'recalca', 'censura', 'abstrai', 'mascara', 'esconde'. Na verdade, o poder produz realidade, produz campos de objetos e rituais da verdade. O indivíduo e o conhecimento que dele se pode ter se originam nessa produção (FOUCAULT, 1984, p. 172).

Nessa perspectiva que envolve os efeitos de poderes nas relações sociais, há também a produção de saberes e prazeres disciplinares que iriam constituir domínios de conhecimentos e iriam disciplinar, além dos corpos, as próprias populações (FOUCAULT, 1982). Nessa configuração, os controles exercidos pelas disciplinas iriam forjar uma sociedade de controle biopolítico e de enfraquecimento das potencialidades criativas e inventivas humanas. Segundo Foucault (2002), as estratégias de controle biopolítico teriam seu surgimento na mesma época da sociedade disciplinar e teriam como principal característica o gerenciamento da população:

Concretamente, esse poder sobre a vida desenvolveu-se a partir do século XVII, em duas formas principais; que não são antitéticas e constituem, ao contrário, dois pólos de desenvolvimento interligados por todo um feixe intermediário de relações. Um dos pólos, o primeiro a ser formado, ao que parece, centrou-se no corpo como máquina: no seu adestramento, na ampliação de suas aptidões, na extorsão de suas forças, no crescimento paralelo de sua utilidade e docilidade, na sua integração em sistemas de controle eficazes e econômicos - tudo isto assegurado por procedimentos de poder que caracterizam as disciplinas: anátomo-politica do corpo humano. O segundo, que se formou um pouco mais tarde, por volta da metade do século XVIII, centrou-se no corpo-espécie, no corpo transpassado pela mecânica do ser vivo e como suporte dos processos biológicos: a proliferação, os nascimentos e a mortalidade, o nível de saúde, a duração da vida, a longevidade, com todas as condições que podem fazê-los variar; tais processos são assumidos mediante toda uma série de intervenções e controles reguladores: uma bio-política da população. (FOUCAULT, 1997, p. 131, grifo do autor).

Nessa configuração, as sexualidades também seria tema de abordagem da medicina e de tecnologias que estariam no âmbito desses processos de medicalização da vida humana e das estratégias de controle biopolítico, em consonância com a patologização dos fenômenos da existência humana.

\section{As origens da medicalização da sexualidade e as estratégias de controle biopolítico}

No final do séc. XVIII e início do séc. XIX, a sexualidade deixaria de ser um aspecto comum e indiferenciado do cotidiano das mulheres e dos homens para ser transformada em um dispositivo submetido aos discursos disciplinares e de controle social (TONELI, 2007). Conforme Foucault (1997), esse seria um período em que os discursos disciplinares de saber-poder-prazer permitiriam a construção de estratégias de regulação biopolítica que também iriam constituir saberes sobre as sexualidades e suas práticas distribuídas entre as esferas do público e do privado.

$\mathrm{O}$ engendramento de discursos imperativos de saber-poder-prazer sobre as sexualidades estariam relacionados às práticas médicas higienistas e restritas à função procriativa, aliadas ao pensamento cristão, logo, distantes da dimensão dos prazeres que através da normatização dos sexos, da classificação das perversões, do controle das sexualidades consideradas desviantes, forjaria uma "ortopedia do sexo" (FOUCAULT, 1996) que incidiria sobre os corpos por meio da busca dos menores detalhes biológicos e psíquicos para determinar o lugar das sexualidades (TONELI, 2007).

Os dispositivos de normatização sobre os sexos seriam engendrados, conforme Foucault (1997), a partir de quatro grandes conjuntos estratégicos:

Em primeiro lugar, o processo de "histerização do corpo da mulher", pelo qual o corpo da mulher considerado como desprovido de desejo sexual seria definido apenas como um receptáculo da fúria gonádica do homem e a mulher nesse processo deveria estar essencialmente atrelada e reduzida ao espaço familiar e ao cuidado das crianças, estando sempre vigilante quanto a qualquer deslize que demonstrasse indícios na prole de dissidências de sexo/gênero/desejo, pois teria que prestar contas à dominação falocêntrica à qual também fora submetida; em segundo lugar, a "pedagogização do sexo da crian- 
ça", que estaria relacionada a necessidade de atenção aos movimentos e expressões que denunciasse a erotização dos corpos, o auto toque sensual e/ou masturbatórios e/ ou de contatos afetivos, eróticos e sexuais entre crianças, sendo determinado pelo biopoder que pais, educadores, médicos e, mais tarde, psicólogos deveriam se encarregar continuamente do controle disciplinar e regulatório, assim como, dos princípios e da educação sexual das crianças, em consonância com premissas heteronormativas e falocêntricas, reificando o poder do sistema sexo/gênero/ desejo/práticas sexuais como único modelo de organização social e política da população; em terceiro lugar, a "socialização das condutas de procriação" que visavam incentivar ou frear a reprodução dos casais heterossexuais, regulando as práticas sexuais para a procriação de filhas e filhos saudáveis, dentro de um escopo ascético restrito ao sexo reprodutivo cristão; e, em quarto lugar, a "psiquiatrização do prazer perverso", processo relacionado a normalização de comportamentos corretivos no caso daquelas condutas consideradas como anomalias sexuais e que se distanciavam do modelo reprodutivo, em especial, vinculado ao amor e ao sexo entre bio-corpos iguais e em suas respectivas expressões de gênero.

Destarte, podemos evidenciar que o dispositivo da sexualidade estaria, basicamente, organizado em torno da instituição médica, da exigência da normalidade e do controle da vida e da morte, sendo problematizado por Michel Foucault como sendo:

um conjunto decididamente heterogêneo que engloba discursos, instituições, organizações arquitetônicas, decisões regulamentares, leis, medidas administrativas, enunciados científicos, proposições filosóficas, morais, filantrópicas. Em suma, o dito e o não dito são os elementos do dispositivo. O dispositivo é a rede que se pode manter entre esses elementos (FOUCAULT, 1982, p. 244).

Orientados por essa dimensão e do ponto de vista de Rosi Braidotti (2002), em seu Metamorfosis: hacia uma teoria materialista del devenir, esses aspectos que envolveriam o dispositivo da sexualidade também estariam sendo constituídos por meio de discursos monológicos do falocentrismo.

Nessa perspectiva, o processo de medicalização do corpo da mulher, que se originaria no final do sec. XVIII, ainda apresenta características atuais de controle e regulação biopolítica, momento em que a medicina continua a determinar por meio de discursos e práticas morais as condutas sobre as formas mais adequadas de ser mulher relacionada ao seu papel fisiológico procriativo da maternidade e condenando qualquer forma de romper ou qualquer possibilidade de escolha sobre esse papel, inviabilizando qualquer possibilidade de problematizar a experiência da maternidade e dos prazeres em uma perspectiva dos direitos sexuais, o que por sua vez reifica as desigualdades sociais e as iniquidades de gênero em um viés machista e misógino.

Os movimentos de enfrentamento às estratégias de medicalização dos corpos das mulheres não são recentes, mas tomam evidência em meados do século XX quando em diversos países do mundo, inclusive no Brasil, se organizam movimentos feministas que reivindicam por direitos e demarcam os processos de luta e resistência política e social (RAGO, 2004). Sob o olhar foucaultiano compreende-se que entre as relações de poderes sempre há possibilidades de resistências constituídas pelas forças da criação de alternativas positivas e pelo estabelecimento de transformações estratégicas (FOUCAULT, 1982). No entanto, ressalta-se a existência frequente de inúmeras formas de desqualificação, violência e opressão vivenciadas por mulheres ainda submetidas às práticas misóginas, falocêntricas e machistas presentes na sociedade brasileira e que podem também ser denunciadas pelo atual processo de criminalização do aborto no país.

\section{Alguns apontamentos sobre a criminalização do aborto no Brasil}

A legislação brasileira determina que o aborto é considerado crime contra a vida, salvo três exceções previstas pela lei penal: a primeira resulta da gravidez em decorrência de estupro, a segunda refere-se aos casos de riscos de vida da mulher grávida e a terceira, em recente decisão da justiça brasileira, somente admitida por meio de decisões judiciais, refere-se a malformação fetal incompatível com a vida extra-uterina (TORRES, 2012).

No Brasil, conforme Scavone (2008), o aborto é um crime raramente punido. Entretanto, as impossibilidades da prática legal em casos mais amplos de uma gravidez indesejada causam constrangimentos tanto às mulheres que o praticam quanto às parteiras que o executam, pois:

não podemos desconsiderar a força simbólica dessa interdição penal sobre o imaginário social e subjetivo de quem o pratica, já que há notificações policiais, processos penais, enfim, todo um aparato criminal disponível em torno do aborto, mesmo que ele não resulte em condenação (SCAVONE, 2008, p. 675).

Uma das grandes problemáticas desse processo de criminalização do aborto está relacionada ao número elevado de complicações decorrentes do abortamento e à alta taxa de mortalidade de mulheres, principalmente, pobres que praticaram o aborto em condições clandestinas (WIESE; SALDANHA, 2014). Conforme Diniz e Medeiros (2010), uma em cada cinco mulheres brasileiras realizou pelo menos um aborto na vida, informações que claramente evidenciam a questão do abortamento como um problema de saúde pública. As dificuldades do levantamento do número de mulheres mortas devido às complicações do aborto ilegal são reconhecidas pela literatura especializada, mas dados estimados sugerem que essa seja a quinta causa de "morte materna" no país (VARELLA, 2015). Conforme aponta Scavone (2008), esses altos índices de morte, além de outros fatores relacionados a questão da legalização e descriminalização do aborto, levariam os movimentos feministas contemporâneos a reivindicarem pelo direito individual da mulher, ou seja, reivindicar pelo

princípio democrático liberal do direito aplicado ao corpo; direito baseado nas idéias de autonomia e liberdade do liberalismo, expresso na máxima feminista "nosso corpo nos 
pertence", que se difundiu internacionalmente a partir dos países centrais e marcou as lutas feministas relacionadas à sexualidade, à contracepção e ao aborto. A apropriação do corpo também significava para as mulheres a possibilidade da livre escolha da maternidade (SCAVONE, 2008, p. 677).

É preciso considerar que as lutas e reivindicações pelo direito ao corpo, por meio dos diversos movimentos feministas, trouxeram e ainda apresentam significativas atualizações no sentido de contribuir para o "processo de desterritorialização do corpo da mulher" do âmbito dos discursos hegemônicos (BRAIDOTTI, 2000) e tradicionais que envolvem o aborto (AZEVEDO; GARCIA, 2008). "O slogan 'Pelo direito de decidir' é até hoje emblemático e representativo das reivindicações feministas para garantir o direito ao próprio corpo e se mantém constante no polêmico debate envolvendo a legalização do aborto e sua descriminalização" (AZEVEDO; GARCIA, 2008, p. 4).

Entretanto, é preciso destacar que os altos índices de morte entre mulheres que praticaram e praticam o aborto está entrelaçado, principalmente, às condições de miséria e pobreza dessas mulheres que não tiveram acesso ou condições financeiras para arcar com despesas em clínicas médicas clandestinas e particulares destinadas, principalmente, a população de alta renda. Essas mulheres submetidas às agulhas de tricô introduzidas no útero, às beberagens com chás de mamona e cupim, às medicações como o "Citotec" e os cristais de permanganato introduzidos no canal da vagina e que causam lesões crônicas nessa mucosa, são em sua maioria mulheres pobres que sem acesso a serviços que as atendam para a prática de tal procedimento se submetem e arriscam suas vidas.

O processo de criminalização do aborto está relacionado aos domínios jurídicos, médicos e, principalmente, morais que apresentados pelos discursos religiosos influenciam as decisões legislativas e, consequentemente, de atendimento à saúde dessa população. Conforme Azevedo e Garcia (2008, p. 6), "a questão do aborto no Brasil se mantém de forma hegemônica circunscrita ao debate em torno da moral e do poder regulador de instituições como a Igreja". A Igreja Católica, principalmente ao longo do século XX, ampliou e difundiu as discussões sobre questões sexuais e reprodutivas e se colocou em oposição ao controle de natalidade por meio do uso de métodos contraceptivos (BIROLI, 2014). Pautada nas concepções de composição de uma família nuclear burguesa convencional e de ordem sexual conservadora relacionada ao casamento entre homem e mulher, acentuou-se, então, o papel da maternidade da mulher como algo da "natureza feminina". Ideais religiosos que influenciam valores, crenças e concepções da sociedade brasileira ao definir a prática do abortamento como da ordem pecaminosa e de desvalorização da vida, e que inspiram posicionamentos médicos e jurídicos legitimados pelo Estado que deveria ser laico, mas criminaliza o aborto no país. Além disso, a presença de valores e protagonistas religiosos na esfera pública e política no Brasil, principalmente da denominada "bancada evangélica", dificulta os debates sobre o tema da legalização do aborto e enfatiza os processos de criminalização encobrindo a realidade de centenas ou milhares de mulheres que morrem em decorrência do descaso do Estado que não reconhece a gravidade e urgência de políticas de proteção e defesa da vida dessas pessoas.

É preciso ressaltar que muitas dos aspectos morais que envolvem os discursos de defesa ao aborto como crime e como pecado tiveram sua origem nesse processo de medicalização do corpo da mulher sob forte influência dos discursos morais cristãos. No resgate dessa trajetória das origens dos processos de medicalização das sexualidades e, mais especificamente, do corpo da mulher, encontramos naqueles saberes e discursos científicos médicos higienistas o modelo normativo de mulher frágil, afetiva, assexuada, esposa-mãe-dona-de-casa (COSTA et. al., 2006), que as exclui completamente de direitos políticos de cidadania e autonomia. Conforme Rago (2006, p. 79), em seus estudos sobre a constituição dos discursos médicos sobre o papel da mulher brasileira no início do sec. XX, "não amamentar e não ser esposa e mãe significava desobedecer a ordem natural das coisas, ao mesmo tempo que punha em risco o futuro da nação". Esses procedimentos normativos e esse modelo de mulher, ainda nos tempos atuais, influenciam as características daquilo que se considera "ser mulher", papel restrito, na maioria das vezes, às referências da mulher branca, heterossexual, cristã, de classe média, submissa, passiva e procriadora.

\section{Reflexões sobre a questão do aborto e da medicalização do corpo da mulher}

"Não se nasce mulher: torna-se mulher"
O Segundo Sexo - de Simone de Beauvoir (1980)

"Ser mulher" não está relacionado a uma essência biológica pré-determinada, mas a uma identidade construída social e culturalmente a partir das relações sociais e sexuais e pelas práticas e discursos dos saberes disciplinares (BRAIDOTTI, 2000). Conforme Haraway (2000), seriam os discursos científicos sobre a sexualidade e outras práticas sociais que iriam determinar o que é "ser mulher"....

Não existe nada no fato de ser "mulher" que naturalmente una as mulheres. Não existe nem mesmo uma tal situação - "ser" mulher. Trata-se, ela própria, de uma categoria altamente complexa, construída por meio de discursos científicos sexuais e de outras práticas sociais questionáveis. (HARAWAY, 2000, p. 52).

Nessa configuração, Donna Haraway (2000) considera importante tentar romper com as definições que aprisionam as mulheres, por isso a autora trabalha com aquilo que denomina de "identidades fraturadas", no sentido de pensarmos em afinidades e não identidades para a construção dos "nós" feministas.

Em consonância com a proposição de Haraway, Judith Butler (2003) nos dirá que a categoria mulher, mesmo no plural, mulheres, é uma idéia vazia e por isso necessita de atributos que possam materializá-la politicamente de modo a lhe dar consistência conceitual e existencial. 
De acordo com Butler (2003) a teoria feminista supõe que exista uma identidade feminina que se deriva da categoria mulher, o que por sua vez a constitui como sujeito, mas a própria noção do que se considera mulher tem sofrido abalos e tremores ao longo do tempo que a desestabiliza e enfraquece diante das tentativas de se apresentar como algo definido, absoluto e universal, e, por isso mesmo, adverte-nos que:

Se alguém "é" uma mulher, isso certamente não é tudo o que esse alguém é; o termo não logra ser exaustivo, não porque os traços pré-definidos de gênero da "pessoa" transcendam a parafernália de seu gênero, mas porque o gênero nem sempre se constitui de maneira coerente ou consistente nos diferentes contextos históricos, e porque o gênero estabelece interseções com modalidades raciais, classistas, étnicas, sexuais e regionais de identidades discursivamente constituídas. Resulta que se tornou impossível separar a noção de "gênero" das interseções políticas e culturais em que invariavelmente ela é produzida e mantida (BUTLER, 2003, p. 20).

A ideia de mulher e de subjetivação feminina só pode ser demarcada através da construção psico-sócio-histórica, ou seja, sempre de forma negociada de acordo com os discursos de saber-poder-prazer que estabelecem os processos de normatização e de singularização de cada contexto em que surge a necessidade de clarificação conceitual. Neste sentido, a ideia de mulher precisa ser vista nas complexidades que a definem de acordo com os marcadores sociais que a compõe e gerencia as escalas desiguais de direitos, ou seja, intercessões com classe, raça/côr, sexo, gênero, idade, estado civil, escolaridade, aspectos que participam dos processos de subjetivação e autorizam práticas que tanto emancipam como aprisionam os corpos, os prazeres, os desejos, os pensamentos, e que podem estar restritos aos regimes de verdades que se materializam na identidade.

Os aprisionamentos identitários seriam consequências de processos de hierarquização, adestramentos e disciplinarização dos corpos (biopoder), e de regulação e controle dos prazeres (biopolítica), de modo a dar manutenção à heterossexualidade como obrigatória, o que implica em scripts ritualísticos - namoro, noivado, casamento, família, filhos, netos - em consonância com preceitos cristãos de sustentação de práticas sexuais restritas à procriação e reprodução da espécie.

Para a efetivação dessas competências Judith Butler (2003) nos adverte a respeito do que define como sistema sexo/gênero/desejo/práticas sexuais; esse sistema fundamentado por premissas médicas e religiosas seria responsável pelo estabelecimento de regras e procedimentos que inscrevem nos corpos das mulheres e dos homens imperativos que dão às pessoas, e às mulheres em especial, a referência de um corpo que tem como destino a gestação e a reprodução humana como função e obrigação, em decorrência de ser mulher; essas determinações se intensificam através de figuras e estereótipos de gênero centrado nas imagens de "Eva" e de "Maria - Nossa Senhora", impregnados por signos de pureza, passividade e resignação, que fixam pressupostos da concepção cristã produtoras em si mes- mo de sentimentos de culpa, baixa estima e de que seria merecedora de castigo, diante de qualquer dissidência que possa aproxima-la de pensamentos e ações que se voltam para o abortamento.

O corpo da mulher é tratado como "santo" e inviolável, logo, destituído de valor político, histórico e cultural resultando em identidades dadas como acabadas e universais. Trata-se de alianças entre a medicina e a igreja que subjetivam corpos contidos, dóceis e obedientes, passivos diante das determinaçoes morais que toma a gestação como efeito do sagrado e que se confunde com a máxima do corpo saudável, criando a ilusão que une maternidade - dom divino.

Em sentido crítico, Braidotti $(2002,2004)$ considera que as identidades não devem ser compreendidas como uma essência fixa, do tipo biológica, psíquica ou histórica, pelo contrário, as identidades se constroem por meio de práticas sociais e discursivas atreladas aos poderes falocêntricos. Dessa forma, quando se pensa em identidades

não se trata de desenvolvermos uma pergunta essencialista: o que é a identidade nacional ou ética? Ou, o que é uma mulher? O que é um homem? Do contrário, cabe melhor uma pergunta crítica e genealógica: como a identidade é construída? Por quem? Sob que condições? Para que fins? (BRAIDOTTI, 2004, p. 206).

Embora a ideia de identidade esteja presente na maioria das formulações de referência nos mais variados saberes instituídos como regimes de verdade, sua produção se faz através de comparações binárias que contribuem para a manutenção de escalas de desigualdades que reificam corpos, sensações, pensamentos e desejos restritos a heteronormatividade e ao falocentrismo.

Surge a necessidade de pensarmos sobre a mulher, o homem a heterossexualidade, a homossexualidade, o masculino, o feminino para além das amarras dicotômicas e universalizantes, pois, como aponta Foucault (1997):

Não se deve fazer divisão binária entre o que se diz e o que não se diz; é preciso tentar determinar as diferentes maneiras de não dizer, como são distribuídos os que podem e não podem falar, que tipo de discurso é autorizado ou que forma de discrição é exigida a uns e outros. Não existe um só, mas muitos silêncios e são parte integrante das estratégias que apoiam e atravessam os discursos (FOUCAULT, 1997:30).

Nesse sentido de rompimento com a lógica binária constituída por esses discursos falocêntricos, Braidotti (2000) comenta que a corporificação dos sujeitos não deve ser compreendida como uma categoria biológica ou sociológica, mas como um ponto de conexão entre o físico, o simbólico e o sociológico. Nessa perspectiva, é necessário considerar as diferenças sociais e culturais que irão constituir o que é ser mulher e o que é ser homem para além de uma realidade homogênea e monolítica. Segundo Braidotti (2000, p. 30),

o sujeito mulher não é tomado como uma essência monolítica definida de forma acabada, mas como um conjunto de experiências múltiplas, complexas e potencialmente contraditórias, definidas por variáveis que se superpõe tais como, classe, raça, idade, estilo de vida, gênero, a preferên- 
cia sexual e outras.

No Brasil, as questões referentes aos gêneros, classes e raças/cores são aspectos discutidos de forma fragmentada entre as feministas. Em um país como o nosso em que a experiência da escravidão foi tão marcante, a questão racial e de classe permanece silenciada no âmbito das pesquisas e estudos feministas em interfaces com a Psicologia e em outros saberes. Algo que para Haraway (2000, p. 52) torna o conceito de mulher algo escorregadio e que culmina, consequentemente, na dominação que algumas mulheres exercem e submetem outras:

A consciência de classe, de raça ou de gênero é uma conquista que nos foi imposta pela terrível experiência histórica das realidades sociais contraditórias do capitalismo, do colonialismo e do patriarcado [...]. A existência de uma dolorosa fragmentação entre as feministas (para não dizer "entre as mulheres"), ao longo de cada fissura possível, tem feito com que o conceito de mulher se torne escorregadio: ele acaba funcionando como uma desculpa para a matriz das dominações que as mulheres exercem umas sobre as outras.

Nessa configuração, considera-se que o processo de criminalização do aborto no Brasil que, sem dúvida, afeta todas as mulheres, será muito mais marcante naquela população feminina caracterizada pela miséria e pobreza, pois será essa a população que sofrerá com mais danos à saúde e mortes após a prática do aborto. Assim como, os processos de culpabilizações, relacionados aos discursos da moral cristã, se efetivam muito mais nas mulheres do que nos homens, quando muitas das vezes a responsabilidade e a escolha pela opção do abortamento ficam reduzidas "a decisão da mulher", no qual o homem participante do processo se situa como mero expectador, evidenciando os efeitos regulatórios médicos e religiosos que se incidem sobre qualquer decisão.

Dessa forma, a vida de determinadas parcelas da população brasileira vale somente no âmbito de sua exclusão, seja ela social, física, cultural, moral ou política (SANCHES, 2010). Nessa perspectiva, a metáfora do homo sacer, explorada por Agamben (2002), cabe perfeitamente para compreendermos como sociedade e Estado ignoram todos os aspectos que circundam a prática do aborto. Segundo Agamben (2002), homo sacer, ou homem sagrado, era uma obscura figura do direito romano para designar todos aqueles que poderiam ser mortos sem que isso fosse caracterizado como um ato de violação ou homicídio. A vida daquelas pessoas se resumia a seu "caráter inumano", por isso a possibilidade de ser extinta por qualquer motivo. Nas palavras de Pelbart (2003, p. 61-62):

O homem sacro é aquele que, julgado por um delito, pode ser morto sem que isso constitua um homicídio, ou uma execução, ou uma condenação, ou um sacrilégio, nem sequer um sacrifício. Subtrai-se assim à esfera do direito humano, sem por isso passar à esfera do direito divino. Essa dupla exclusão é, paradoxalmente, uma dupla captura: sua vida, excluída da comunidade por ser insacrificável, é nela incluída por ser matável. A vida nua está, desse modo, desde o início numa relação de exceção com o poder soberano, numa interdependência recíproca que pode ser expressa do seguinte modo: 'Soberania é a esfera na qual se pode matar sem cometer um homicídio e sem celebrar um sacrifício, e sacra, isto é, matável e insacrificável, é a vida que foi capturada nesta esfera'.

Dessa forma, aquelas mulheres pobres que optam pela prática do aborto e que, sem condições para arcar com as despesas financeiras para um atendimento e cuidado de saúde, se submetem as precárias formas de descontinuação da gravidez e são brutalmente vítimas dessa opção, podem perfeitamente serem representadas pela metáfora do homo sacer. A "vida matável" (AGAMBEN, 2002) daquelas mulheres não está somente desprovida de direitos, mas da própria qualidade do humano, do cidadão, pois pode ser eliminada ou extinta sem qualquer prejuízo ou relevância para a sociedade.

Nessa configuração, é importante tentarmos superar os obstáculos referentes à luta contra a criminalização do aborto e medicalização do corpo feminino, que leva mulheres a se submeterem aos discursos morais e falocêntricos e às práticas violentas e mortais. Entretanto, não basta a descriminalização do aborto no âmbito legislativo e a criação de intervenções médicas em serviços de saúde públicos para atender aquelas mulheres que optarem pelo aborto, é preciso romper com preconceitos relacionados às figurações do que é "ser mulher" e dos predicados higienistas e ascépticos que lhes são determinados. É preciso construir programas e currículos laicos que privilegiem os direitos sexuais como direitos humanos, de respeito à singularidade de mulheres que ousam tomar as rédias do destino de suas vidas e de seus desejos.

Longe de tentarmos dar explicações simples para um processo tão complexo, as reflexões de Rosi Braidotti nos convidam a pensar no movimento de romper com identidades hegemônicas, relacionadas a função de cumprir com o papel de "ser mulher" nos tempos atuais, para construirmos aquilo que a própria autora denominou de construção de figurações nômades. Segundo Braidotti (2000), ser um sujeito nômade significa estar em trânsito, sem se desresponsabilizar e se desvincular de sua posição psicossocial, histórica, política e cultural. O nômade permite analisar as categorias estabelecidas, borrar fronteiras sem desmanchar as pontes de conexão, libertar-se dos jogos do dogmatismo falocêntrico para constituir subjetividades potentes. Nas palavras da própria autora: “A consciência nômade é uma forma de resistência política a toda visão hegemônica e excludente da subjetividade" (BRAIDOTTI, 2004, p. 216).

\section{À guisa de conclusão}

O processo de medicalização da sexualidade e de controle e regulação dos corpos de mulheres, originado na passagem do século XVIII para o século XIX, iria determinar por meio de saberes disciplinares médicos e moralizantes aquilo que seria considerado como comportamento normal e adequado para a natureza dos corpos femininos, tendo ainda hoje consequências encontradas 
nas práticas corporais e sexuais que só podem ser vistas como entrelaçadas ao papel da maternidade, da família, da esposa subalterna ao marido. Esses discursos médicos e moralistas, difundidos pelos movimentos higienistas influenciariam grandes contingentes populacionais e estariam presentes, ainda que por meio de outras roupagens, nos discursos morais normativos sobre os papéis impostos para as mulheres em nossa atualidade.

As estratégias de controle biopolítico, determinadas pelos saberes disciplinares e que pretendem gerenciar e regular a população por meio dos processos que envolvem a vida e também a morte, irão reger os corpos, seus prazeres e todos os seus processos biológicos, mas também visam a produção dos sistemas de pensamentos e de percepção e gerenciam as relações sociais e as demandas políticas de emancipação. A determinação do controle regulador sobre os nascimentos, a morte, a duração de vida, a longevidade, as práticas sexuais, as expressões de gênero, as intesidades e modos dos prazeres, inclusive sobre quem deverá ser excluído e quem deverá ser incluído nos esquemas de reconhecimento e respeitabilidade social, quem deverá nascer e quem deverá morrer estarão relacionados ao manejo biopolítico. Destarte, a criminalização do aborto no Brasil também será um processo submetido a essas estratégias biopolíticas que permitirá que inúmeras mulheres pobres sejam mortas pela prática do aborto, ou ainda, desqualificadas por suas dissidências do desejo e da moral.

A legitimação da violência, opressão e desrespeito com a vida de mulheres pobres que optam pelo aborto e não podem ser atendidas em serviços públicos de saúde, salvo os casos de estupro, risco de vida e comprovada malformação do feto, são aspectos que denotam o "caráter matável" dessas mulheres e que as qualificam como abjetas, como pré-sujeitos que, por si mesmas, são desprovidas de direitos a ter direitos.

Sem dúvida, o caminho para o processo de descriminalização passaria pelos dispositivos médicos, mas também pela ruptura da moral cristã vigente, e pelas mudanças de paradigmas e de mentalidades, o que possibilitaria se pensar na prática do aborto não mais no âmbito do crime e da moral, mas sim no âmbito da saúde e do direito. Nessa perspectiva, os serviços da rede do Sistema Público de Saúde (SUS) no Brasil poderiam oferecer o atendimento, quando métodos contraceptivos não funcionarem, para todas aquelas mulheres que queiram optar pela prática do aborto, sem discriminação de raça, credo, etnia e classe social. Entretanto, a descriminalização do aborto também deverá significar o rompimento com concepções sobre o processo de "histerização do corpo da mulher", da lógica falocêntrica e dos discursos médicos morais que vão dizer sobre o que é "ser mulher". Resgatando concepções deleuzianas, a partir dos apontamentos de Rosi Braidotti, é preciso começar a pensar de maneira diferente de nossa condição histórica, para podermos nos reinventar e recriar continuamente figurações nômades com o intuito de promover resistências aos poderes constituídos e que submetem mulheres.

\section{Referências}

AGAMBEN, G. Homo Sacer: poder soberano e vida nua. Belo Horizonte: UFMG, 2002. v. 1.

AZEVEDO, S. R. S.; GARCIA, L. G. Discursos sobre o aborto na imprensa paraibana. In: SEMINÁRIO INTERNACIONAL FAZENDO GÊNERO: CORPO, VIOLÊNCIA E PODER, 8., 2008, Santa Catarina. Anais... Santa Catarina: UFSC, 2008. Disponível em: <http://www.fazendogenero.ufsc.br/8/sts/ ST39/Azevedo-Garcia_39.pdf>. Acesso em: 22 dez. 2011.

BRAIDOTTI, R. Sujetos nómades: corporización y diferencia sexual em la teoria feminista contemporânea. Buenos Aires: Paidós, 2000.

BRAIDOTTI, R. Metamorfosis: hacia uma teoria materialista del devenir. Madrid: Alcal, 2002.

BRAIDOTTI, R. Las figuraciones del nomadismo. In: Feminismo, diferencia sexual y subjetividad nómade. Madrid: Gesida, 2004. p. 201-226.

BEAUVOIR, S. O Segundo Sexo. Tradução de Sérgio Milliet. Rio de Janeiro: Nova Fronteira, 1980. v. I, II.

BIROLI, F. Autonomia e justiça no debate sobre aborto: implicações teóricas e políticas. Revista Brasileira de Ciência Política, Brasília, n. 15, p. 37-68, set./dez. 2014.

BUTLER, J. Problemas de gênero: feminismo e subversão da identidade. Rio de Janeiro: Civilização Brasileira, 2003.

CASTEL, R. A ordem psiquiátrica: a idade de ouro do alienismo. Rio de Janeiro: Graal, 1978.

COSTA, T. et al. Naturalização e medicalização do corpo feminino: o controle social por meio da reprodução. Revista Interface - Comunicação, Saúde, Educação, [S.1.], v. 10, n. 20, p. 363-380, jul./dez., 2006. Disponível em: $\quad<$ http://www.scielo.br/scielo.php?script=sci arttext\&pid=S1414-32832006000200007>. Acesso em: 24 jan. 2012.

DELEUZE, G. Post-scriptum sobre as sociedades de controle. In: 1999. . Conversações: 1972-1990. Rio de Janeiro: Ed. 34,

DINIZ, D.; MEDEIROS, M. Aborto no Brasil: uma pesquisa domiciliar com técnica de urna. Ciência \& Saúde Coletiva, [S.1.], n. 15, supl. 1, p. 959-966, 2010. Disponível em: <http:// www.apublica.org/wp-content/uploads/2013/09/PNA.pdf $>$. Acesso em: 25 abr. 2015.

FOUCAULT, M. Microfísica do Poder. Rio de Janeiro: Graal, 1982.

FOUCAULT, M. Vigiar e punir: história da violência nas prisões. 3. ed. Petrópolis, RJ: Vozes, 1984.

FOUCAULT, M. A verdade e as formas jurídicas. Rio de Janeiro: Nau, 1996.

FOUCAULT, M. História da sexualidade: a vontade de saber. Rio de Janeiro: Graal, 1997. v. 1.

FOUCAULT, M. Em defesa da sociedade: curso no Collège de France (1975-1976). São Paulo: Martins Fontes, 2002.

FOUCAULT, M. O poder psiquiátrico: curso no Collège de France (1973-1974). São Paulo: Martins Fontes, 2006. 
FOUCAULT, M. Crise da medicina ou crise da antimedicina. Revista Verve, [S.1.], v. 18, p. 167-194, 2010. Disponível em: $<$ http://revistas.pucsp.br/index.php/verve/article/view/8646>. Acesso em: 26 nov. 2011.

GALINDO, D.; LEMOS, F. C. S.; RODRIGUES, R. V. Do poder psiquiátrico: uma analítica das práticas de farmacologização da vida. Mnemosine, Rio de Janeiro, v. 10, n. 1, p. 98-113, 2014.

HARAWAY, D. Manifesto ciborgue: ciência, tecnologia e feminismo-socialista no final do século XX. In: TADEU, T. (Org.). Antropologia do ciborgue: as vertigens do pós-humano. Belo Horizonte: Autêntica, 2000. p. 33-118.

HORA, D. M. Medicalização. Glossário do Grupo de Estudos e Pesquisas História, Sociedade e Educação no Brasil (HISTEDBR). Faculdade de Educação da Unicamp, 2006. Disponível em: <http:www.histedbr.fae.unicamp.br/ navegando/glossario/verb_c_medicalizacao.htm $>$. Acesso em: 06 de abril de 2009.

ILLICH, I. A expropriação da saúde: nêmesis da medicina. Tradução de José Kosinski de Cavalcanti. 3. ed. Rio de Janeiro: Nova Fronteira, 1975.

MACHADO, R. Ciência e saber: a trajetória da arqueologia de Michel Foucault. Rio de Janeiro: Graal, 1982.

PELBART, P. P. Vida Capital: ensaios de biopolítica. São Paulo: Iluminuras, 2003.

POLI NETO, A.; CAPONI, S. Medicalização: definições e conceitos. In: TESSER, C. (Org.). Medicalização social e atenção à saúde no SUS. São Paulo: Hucitec, 2010.

RAGO, M. Feminismo e subjetividade em tempos pósmodernos. In: COSTA, C. L.; SCHMIDT, S. P. (Org.). Poéticas e politicas feministas. Florianópolis: Mulheres, 2004. p. 31-41.

RAGO, M. Do cabaré ao lar: a utopia da cidade disciplinar. Brasil 1890-1930. Rio de Janeiro: Paz e Terra, 2006.

SCAVONE, L. Políticas feministas do aborto. Revista Estudos Feministas, [S.1.], v. 16, n. 2, p. 675-680, maio/ago. 2008.

SANCHES, R. R. Delenda proibicionismo: apontamentos críticos ao dispositivo de "guerra às drogas". 2010. Dissertação (Mestrado)-Universidade Estadual Paulista, Assis, SP, 2010.

TESSER, C. D. (Org.). Medicalização social e atenção à saúde no SUS. São Paulo: Hucitec, 2010.

TOASSA, G. Sociedade tarja preta: uma crítica à medicalização de crianças e adolescentes. Fractal, Rev. Psicol., Niterói, v. 24, n. 2, p. 429-434, maio/ago. 2012. Disponível em: $<$ http://www. uff.br/periodicoshumanas/index.php/Fractal/article/view/845>. Acesso em: 16 de outubro de 2012.

TONELI, M. J. F. Sexualidade, gênero e gerações: continuando o debate. In: JACÓ-VILELA, A. M.; SATO, L. (Org.). Diálogos em Psicologia Social. Porto Alegre: Evangraf, 2007. p. 141156.

TORRES, J. H. R. Aborto e legislação comparada. Ciência e Cultura, [S.1.], v. 64, n. 2, p. 40-44, abr./jun. 2012.

VARELLA, D. Medicina policialesca. Folha de São Paulo. São Paulo, 07 de março de 2015. Disponível em: <http://www1. folha.uol.com.br/colunas/drauziovarella/2015/03/1599282medicina-policialesca.shtml>. Acesso em: 26 maio 2015.

WIESE, I. R. B.; SALDANHA, A. A. W. Aborto induzido na interface da saúde e do direito. Saúde Soc. São Paulo, v. 23, n. 2, p. 536-547, 2014.

Fractal, Rev. Psicol., v. 28 - n. 1, p. 17-25, 2016
Recebido em: 25 de outubro de 2012 Aceito em: 23 de maio de 2015 